\title{
Daily Hazelnut Intake Exerts Multiple Reversible Effects on Plasma Profile of Healthy Subjects
}

\author{
Chiara Santi' ${ }^{1}$, Antonio Giorni ${ }^{2}$, Caterina Toriani Terenzi ${ }^{2}$, Pierluigi Altavista ${ }^{3}$, \\ Loretta Bacchetta ${ }^{*}$
}

\begin{abstract}
${ }^{1}$ Department of Sustainable Productive and Territorial Systems, Laboratory of Bioprocesses and Bioproducts, ENEA Italian National Agency for New Technologies, Energy and Sustainable Economic Development, Rome, Italy ${ }^{2}$ Services and Infrastructures Central Direction, Management Service and Registered Office, ENEA Italian National Agency for New Technologies, Energy and Sustainable Economic Development, Rome, Italy ${ }^{3}$ Division of Health Protection Technologies, ENEA Italian National Agency for New Technologies, Energy and Sustainable Economic Development, Rome, Italy
\end{abstract}

Email: *loretta.bacchetta@enea.it

How to cite this paper: Santi, C., Giorni, A., Terenzi, C.T., Altavista, P. and Bacchetta, L. (2017) Daily Hazelnut Intake Exerts Multiple Reversible Effects on Plasma Profile of Healthy Subjects. Food and Nutrition Sciences, 8, 633-646. https://doi.org/10.4236/fns.2017.86045

Received: February 10, 2017

Accepted: June 25, 2017

Published: June 28, 2017

Copyright $\odot 2017$ by authors and Scientific Research Publishing Inc. This work is licensed under the Creative Commons Attribution International License (CC BY 4.0).

http://creativecommons.org/licenses/by/4.0/

\begin{abstract}
Life sciences such as medical, nutritional, and those related to agrarian biotechnologies are experiencing a constant increase. Therefore, food consumption is today related to health state. Aiming to create an innovative spinneret system that defines the tight correlation between high nutritional and nutraceutical value of foods and their beneficial effects on consumer's health state, we tested the effects related to the administration of $40 \mathrm{~g}$ of the Tonda Gentile Romana Italian hazelnut cultivar (Viterbo, Italy). To this end, we enrolled 24 subjects for a period of 14 weeks, based on a crossover design. Although several papers and reviews on hazelnut intake benefits are available, few studies have investigated the effects of hazelnut-enriched diet on plasma key parameters commonly used to ascertain the individual's well-being status. The primary endpoint of the trial was to assess LDL change related to hazelnut administration, which resulted in significant beneficial effects on cholesterol parameters (LDL dropped from $133.09 \mathrm{mg} / \mathrm{dl}$ to $119.18 \mathrm{mg} / \mathrm{dl}$ ). Interestingly, despite within the normal ranges, uric acid and serum creatinine mean values significantly decreased after hazelnut intake. A significant increment was also observed for ALT (from 30.9 U/L to $35.22 \mathrm{U} / \mathrm{L}, \mathrm{P}=0.01$ ), while GGT significantly decreased from $38.04 \mathrm{mg} / \mathrm{dl}$ at $\mathrm{T} 0$ to $35.27 \mathrm{mg} / \mathrm{dl}$ at $\mathrm{T} 1(\mathrm{P}=0.001)$. No significant changes were also observed in azotemia, serum iron, glycemia, AST, total bilirubin, $\mathrm{Hb}$, WBCs, RBCs, platelet count, and total plasma proteins. All the blood parameters analyzed appeared to be reversible after 6 weeks from the end of the treatment. Mann-Whitney U test did not show any
\end{abstract}


significant differences in T0 - T1 $\Delta \%$ LDL considering gender, age and baseline LDL. These findings may be of help in the development of strategies for personalized nutrition and diseases management.

\section{Keywords}

Hazelnut, Cholesterol, Lipid Profile, Personalized Nutrition, Nutraceutical

\section{Introduction}

The rapid increase in nutritional sciences and in medical and agrarian biotechnologies knowledge enlarges the food concept to functional food. This is not intended to satisfy hunger and provide humans with necessary nutrients only, but also to prevent nutrition-related diseases and increase physical and mental wellbeing of consumers.

Several epidemiological studies [1] [2] [3] [4] [5] and clinical trials [6]-[11] demonstrated that dried fruit could have an important role on plasmatic lipids, lowering morbidity and mortality related to cardiovascular diseases (CVDs). In 2011, the European Food Safety Authority (EFSA) allowed an Article 13 claim that the consumption of $30 \mathrm{~g}$ of walnuts in the context of a balanced diet leads to improvement of endothelium-dependent vasodilatation (available at https://www.efsa.europa.eu/it/efsajournal/pub/2032).

Among tree nuts, hazelnuts (Corylus avellana L.,) plays also a major role in nutrition and health as high energetic food, rich in fats and proteins; they are valuable sources of fiber, phytonutrients, and antioxidants such as Vitamin E [12] [13]. The lipid fraction is the main component of the hazelnut kernel, with a unique fatty acids composition: high contents of mono-unsaturated fatty acids (MUFA) and low amounts of saturated fatty acids (SFA). In addition to MUFA, some other bioactive molecules such as tocopherols (in particular $\alpha$-tocopherol) have been reported to reduce plasma total and low-density lipoprotein (LDL) cholesterol concentrations [5]. The authors suggested that the increased MUFA content of LDL due to the increased vitamin E intake during hazelnut-enriched diet period could be more effective in decreasing susceptibility of LDL to oxidation. Nevertheless, a beneficial blood lipid lowering effect was reported by the same authors, for the soluble hazelnut dietary fiber supplementation $(9.7 \mathrm{~g} / 100 \mathrm{~g})$ [5]. Among bioactive food components able to modulate metabolic processes, 18 phenolic compounds were identified and quantitatively determined in 57 hazelnut cultivars by Bacchetta and colleagues during the European AGRI GEN RES 068 SAFENUT project [12]. The main compounds identified belong to four groups: flavan-3-ols (catechin, epicatechin, two procyanidin dimers and three procyanidin trimers); flavonols (myricetin-3-Orhamnoside, quercetin pentoside and quercetin-3-Orhamnoside); benzoic acids (gallic acid and protocatechuic acid); and dihydrochalcones (phloridzin), epigallocatechin-3-gallate and proanthocyanidins were reported by Alavasar and Bolling [14]. In this context, hazel- 
nut mineral composition plays also a key role because of its beneficial anti-oxidant activity in lipid systems [15]. Hazelnut is a rich source of potassium (680 $\mathrm{mg} / 100 \mathrm{~g})$, calcium (114 mg/100g), iron (4.7 mg/100g) [13], magnesium (163 $\mathrm{mg} / 100 \mathrm{~g})$ phosphorus $(290 \mathrm{mg} / 100 \mathrm{~g})$ and zinc $(4.7 \mathrm{mg} / 100 \mathrm{~g})$ [13]. Raw hazelnut may also provide a variety of constituents such as the cardio-protective arginine and important B group vitamins, among them folate $(113 \mu \mathrm{g} / 100 \mathrm{~g})$, being this latter one of the major determinant of DNA methylation [17]. Although several papers and reviews on hazelnut intake benefits are available, few studies have investigated the effects of hazelnut-enriched diet on plasma key parameters commonly used to ascertain the individual's well-being status. This approach, which is a pre-requisite to develop strategies for personalized nutrition and diseases management, could allow a better comprehension of hazelnut effects as functional food model, thereby representing a useful investigation to promote its wider and daily consumption. We aimed to investigate the effects related to hazelnut consumption in healthy subjects on several blood parameters.

\section{Materials and Methods}

\subsection{Subjects}

Fifty voluntaries were recruited from the staff of ENEA Casaccia Research Center and the clinical trial was completed in December 2015. Inclusion criteria included healthy subjects of both sexes, aged between 20 and 70 years old and with a body mass index $(\mathrm{BMI})>19 \mathrm{~kg} / \mathrm{m}^{2}$. The exclusion criteria were as follows: history of coronary vascular disease, cerebrovascular or peripheral diseases, diabetes mellitus (both type-1 and -2), liver disease, autoimmune disease, AIDS or malign neoplasm diagnosis. All subjects were required not to be obese and to avoid alcohol consumption. Among participants, 24 voluntaries (10 females and 14 males) resulted eligible for the investigation; 25 subjects did not satisfy inclusion and/or exclusion criteria; one participant retired after the first stage. However, the enrollment process is summarized in Figure 1.

\subsection{Study Design}

The study was developed according to a crossover scheme. This experimental scheme was created as a double sandwich control for a total of 14 weeks. Furthermore, three study periods were established: baseline (T0), six weeks hazelnut daily administration (T1), and six weeks washout period (T2).

Considering that the standard diet is based on a daily intake of three main meals (i.e., breakfast, lunch, and dinner) and using the indications provided by eligible subjects during food anamnesis, the study was divided in three periods. All diet records were analyzed using DIETOSYSTEM ${ }^{\circledR}$ software to provide an estimation of the daily average energy and nutrient intake. The timeline of the trial was subdivided as follows: subjects were instructed to accomplish a standard diet for the first two weeks (2140.36 kcal per day); after this period (T0), they consumed a 6-week diet enriched with hazelnut (T1); finally, they came back to the standard diet for a final 6-week period (T2). We analyzed the following blood 


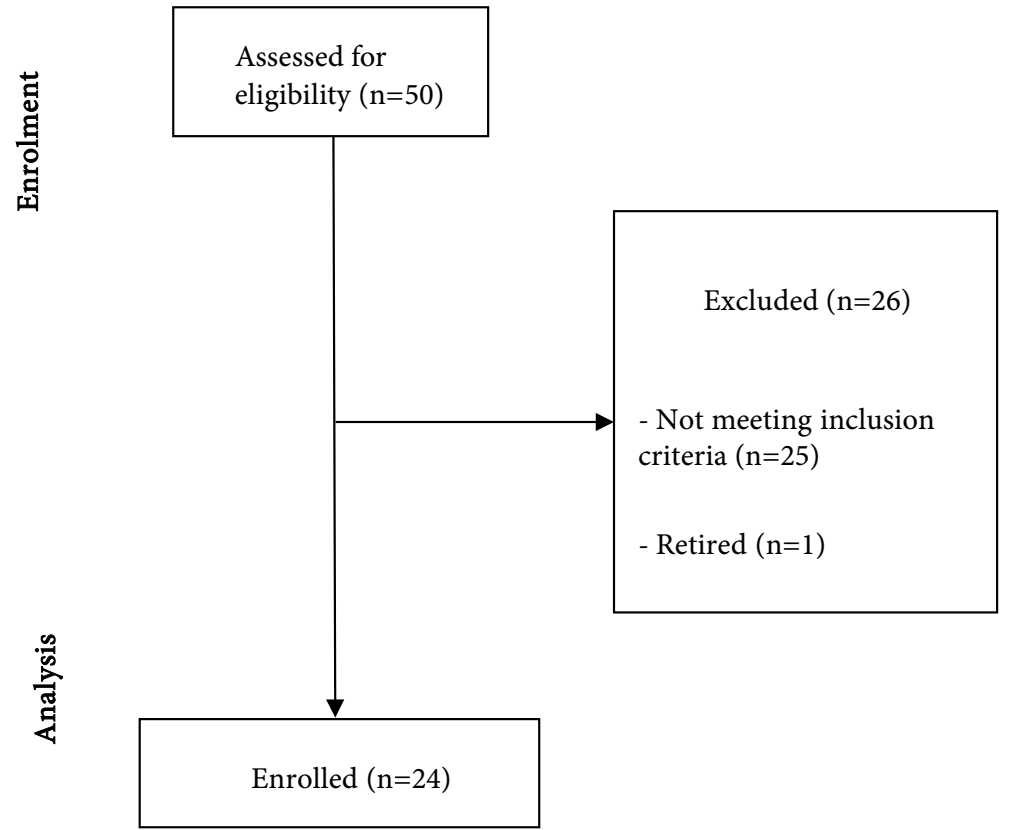

Figure 1. CONSORT flow diagram.

parameters at the end of each diet period: triacylglycerol, total cholesterol, low-density lipoprotein cholesterol (LDL), high-density lipoprotein cholesterol (HDL), glycemia, uric acid, serum creatinine, azotemia, alanine transaminase (ALT), aspartate transaminases (AST), gamma-glutamyl transferase (GGT), serum iron, total bilirubin, hemoglobin $(\mathrm{Hb})$, total plasma protein levels and white blood cells (WBCs), red blood cells (RBCs), and platelets (PLTs) counts in healthy voluntaries. The results were compared among the three considered periods. Each participant was provided a food diary to take note of any adverse effect during the trial. Subjects were individually trained on how to complete the food diary. In addition, they were also instructed to maintain their usual level of physical activity.

Hazelnuts, cultivar Tonda Gentile Romana, were provided by Producer Association of Coopernocciola in Vico Matrino (Viterbo, Italy). The daily hazelnut supplement was provided to each participant as raw shelled hazelnuts in pre-weighed vacuum packages of 40 grams, to be assumed as snack and according to subject's preferences. All participants were asked to eliminate hazelnuts and other nuts from their diet other than those provided by the study. The consumption of chocolate was forbidden, as well as the use of alcohol. The planned nutrient profiles of hazelnut daily intake, equal to $251.2 \mathrm{Kcal} / \mathrm{d}$, were determined at ENEA Casaccia PROBIO Laboratory. The study was discussed with Italian National Institute of Health and according to Italian legislative decree no. 211 of 24 June 2003 was carried out following the written informed consent procedure.

\subsection{Biochemical Blood Analyses}

Biochemical blood analyses were carried out by Services and Infrastructures 
Central Direction, Management Service and Registered Office at ENEA Casaccia Research Center. Fasting venous blood samples were drawn at T0, T1, and T2 by authorized personnel from the antecubital vein into vacutainer tubes, containing beads coated with a clotting activator (silicate) (SARSTEDT, Germany). Tubes were centrifuged at $3000 \mathrm{rpm}$ for 15 minutes at $25^{\circ} \mathrm{C}$ after 30 minutes from sampling. Plasma aliquots were stored at $-80^{\circ} \mathrm{C}$ until analysis. Glucose, uric acid, creatinine, transaminases (both ALT and AST), HDL, and total cholesterol concentrations were determined with Ortho Clinical Diagnostics Vitros 250 (USA) on separated serum samples. Glucose concentrations were measured by glucose oxidase and peroxidase reactions; uric acid concentrations by uricase and peroxidase reactions; creatinine concentrations by creatine aminohydrolase, sarcosine oxidase and peroxidase reactions; ALT concentrations by latticodehydrogenase reactions; AST and GGT concentrations by oxaloacetate decarboxylase, pyruvate oxidase and peroxidase reactions; total and HDL cholesterol concentrations by cholesterol ester hydrolase, oxidase and peroxidase reactions; triacylglycerol concentrations by lipase, glycerol kinase, L- $\alpha$-glicerol phosphate oxidase, and peroxidase reactions; total bilirubin concentrations by dyphilline reaction. Finally, LDL cholesterol concentrations were assessed by the Friedewald formula [16], as follows:

$$
\text { [Total cholesterol - HDL cholesterol - (triacylglycerol/5)] }
$$

The blood count analysis was performed with the XS-100i instrument of Sysmex company. Such tool works with the fluorescent flow-cytometry technology. $\mathrm{Hb}$ determination was performed using the method of sodium lauryl sulfate (SLS); serum iron concentrations were measured by Transferrin-Fe ${ }^{3}$ in $\mathrm{pH} 4$, according to the following reaction (whose result is readable with analyzer (Ortho Clinical Diagnostics Vitros 250, USA):

$$
\left[\text { Transferrin }+\mathrm{Fe}^{3}+\text { Ascorbic Acid }+\mathrm{Fe}^{2}+\text { colorant }\right]
$$

Total proteins were measured by dry plates containing Copper Tartrate, which in presence of $\mathrm{LiOH}$ creates a colored compound readable with analyzer (Ortho Clinical Diagnostics Vitros 250 USA). Table 1 shows the normal ranges of biochemical indices.

\subsection{Statistical Analysis}

The sample size was estimated by the $G^{\star}$ Power 3.0 Software [18]. A sample of 24 subjects allows the detection of a minimal effects size of 0.273 in the primary outcome, in a Repeated Measures Analysis of Variance (Repeated Measures ANOVA) with statistical power of 0.80 and significant level of 0.05 . The same number of subjects allows the detection of a minimum effect size of 0.287 in the primary outcome using a non parametric Friedman Test with the same statistical power and significance level [19].

The distribution of variables was tested by the Kolmogor of-Smirnov test. Biochemical parameters corresponding to the three periods studied were analyzed with Repeated Measures ANOVA, followed by Bonferroni post hoc comparisons 
Table 1. Standard range of biochemical blood parameters at ENEA laboratory.

\begin{tabular}{|c|c|}
\hline Blood parameter (unit) & Normal range \\
\hline Total cholesterol (mg/dl) & $140-240$ \\
\hline LDL-cholesterol (mg/dl) & $80-150$ \\
\hline HDL-cholesterol (mg/dl) & $35-85$ \\
\hline Triacylglyerols (mg/dl) & $45-170$ \\
\hline Uric acid (mg/dl) & $2.5-5.7$ \\
\hline Serum creatinine $(\mathrm{mg} / \mathrm{dl})$ & $0.70-1.20$ \\
\hline Azotemia (mg/dl) & $15-50$ \\
\hline Serum iron $(\mathrm{mg} / \mathrm{dl})$ & $37-170$ \\
\hline Glycemia (mg/dl) & $65-110$ \\
\hline $\operatorname{ALT}^{\mathrm{a}}(\mathrm{U} / \mathrm{l})$ & $9-70$ \\
\hline $\operatorname{AST}^{\mathrm{b}}(\mathrm{U} / \mathrm{l})$ & $14-59$ \\
\hline $\mathrm{GGT}^{\mathrm{c}}(\mathrm{U} / \mathrm{l})$ & $8-78$ \\
\hline Total bilirubin (mg/dl) & $0.20-1.30$ \\
\hline $\mathrm{Hb}^{\mathrm{d}}(\mathrm{mg} / \mathrm{dl})$ & $12.2-16.2$ \\
\hline $\mathrm{WBCs}^{\mathrm{e}}(\mu \mathrm{l})$ & $4600-10,200$ \\
\hline $\operatorname{RBCs}^{\mathrm{f}}(\mu \mathrm{l})$ & $4,040,000-5,148,000$ \\
\hline $\operatorname{PLTs}^{g}(\mu \mathrm{l})$ & $142,000-424,000$ \\
\hline Total protein $(\mathrm{mg} / \mathrm{dl})$ & $6-8$ \\
\hline
\end{tabular}

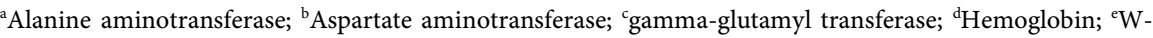

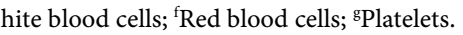

or by Friedman test followed by Wilcoxon test, in case of non-normal distribution of the variable. The value of the Partial Eta Squared was used as effect size measure for Repeated Measures ANOVA [20]. The coefficient of concordance Kendall's W was used to estimate the effect size for the Friedman test. In order to evaluate diet activity on lipid metabolism, the primary endpoint of the trial was the assessment of absolute and relative LDL change between T0 and $\mathrm{T} 1(\Delta \%$ LDL). We calculated the latter as follows:

$$
[100 \times(\text { LDLT1-LDLT0 }) / \text { LDLT0 }]
$$

Moreover, we tested the possible role as effect modifier of age, sex and baseline BMI and LDL values. For that purpose those variables were categorized as follows: baseline LDL $\leq 130$ and $>130 \mathrm{mg} / \mathrm{dl}$; baseline $\mathrm{BMI} \leq 25$ and $>25 \mathrm{~kg} / \mathrm{m}^{2}$; age $\leq$ or $>$ the median value of 55.5 years, males and females, and the mean $\Delta \%$ LDL was compared between each couple of the resulting subgroups, with the Mann-Whitney U test. A P value $<0.05$ was considered as statistically significant in all of the analyses. Data were analyzed by means of SPSS (version for Windows, 17.0).

\section{Results}

Twenty-four healthy subjects completed the trial, as detailed in the study protocol, and the daily hazelnut consumption was well tolerated by all of them. Table 2 
Table 2. Plasma measurements during the three study periods.

\begin{tabular}{|c|c|c|c|c|c|c|c|c|c|c|}
\hline \multirow{2}{*}{$\begin{array}{c}\text { Biochemical } \\
\text { parameter (unit) }\end{array}$} & \multirow[b]{2}{*}{$\mathrm{T}^{\mathrm{a}}$} & \multirow[b]{2}{*}{$\mathrm{T}^{\mathrm{a}}$} & \multirow[b]{2}{*}{$\mathrm{T}^{\mathrm{a}}$} & \multirow[b]{2}{*}{$\begin{array}{c}P \\
\text { value }^{* *}\end{array}$} & \multirow[b]{2}{*}{$x^{2}$} & \multirow[b]{2}{*}{ F } & \multirow[b]{2}{*}{$\begin{array}{l}\text { Effect } \\
\text { size }\end{array}$} & \multicolumn{3}{|c|}{$\begin{array}{l}\text { Post hoc comparisons } \\
\text { across study periods }\end{array}$} \\
\hline & & & & & & & & $\begin{array}{c}\text { T0 vs } \\
\text { T1 }\end{array}$ & $\begin{array}{l}\text { T0 vs } \\
\text { T2 }\end{array}$ & $\begin{array}{c}\text { T1 vs } \\
\text { T2 }\end{array}$ \\
\hline $\begin{array}{l}\text { Total cholesterol } \\
\qquad(\mathrm{mg} / \mathrm{dl})\end{array}$ & $206.04 \pm 40.33$ & $189.43 \pm 44.89$ & $199.56 \pm 37.91$ & 0.004 & & 6.13 & 0.358 & 0.01 & 0.04 & 0.72 \\
\hline $\begin{array}{l}\text { LDL-cholesterol } \\
\qquad(\mathrm{mg} / \mathrm{dl})\end{array}$ & $133.09 \pm 36.52$ & $119.18 \pm 36.66$ & $128.95 \pm 34.38$ & 0.004 & & 7.39 & 0.402 & 0.003 & 0.004 & 0.9 \\
\hline $\begin{array}{l}\text { HDL-cholesterol } \\
\text { (mg/dl) }\end{array}$ & $56.22 \pm 15.34$ & $53.21 \pm 13.89$ & $52.47 \pm 14.01$ & 0.11 & & 2.33 & - & - & - & - \\
\hline LDL/HDL ratio & $2.58 \pm 1.07$ & $2.35 \pm 0.87$ & $2.66 \pm 1.04$ & 0.003 & & 6.87 & 0.384 & 0.02 & 0.004 & 0.9 \\
\hline $\begin{array}{l}\text { Triacylglyerols } \\
\text { (mg/dl) }\end{array}$ & $104.48 \pm 38.44$ & $106.00 \pm 37.90$ & $113.96 \pm 46.69$ & 0.43 & & 0.86 & - & - & - & - \\
\hline $\begin{array}{l}\text { Uric acid } \\
(\mathrm{mg} / \mathrm{dl})\end{array}$ & $4.66 \pm 0.90$ & $4.31 \pm 0.73$ & $4.66 \pm 0.89$ & 0.007 & & 5.51 & 0.334 & 0.025 & 0.99 & 0.013 \\
\hline $\begin{array}{l}\text { Serum creatinine } \\
\qquad(\mathrm{mg} / \mathrm{dl})\end{array}$ & $0.94 \pm 0.18$ & $0.93 \pm 0.15$ & $0.82 \pm 0.18$ & $<0.001$ & 37.72 & & 0.711 & 0.29 & $<0.001$ & $<0.001$ \\
\hline $\begin{array}{l}\text { Azotemia } \\
(\mathrm{mg} / \mathrm{dl})\end{array}$ & $33.01 \pm 9.96$ & $32.13 \pm 9.72$ & $35.5 \pm 12.19$ & 0.10 & & 2.84 & - & - & - & - \\
\hline $\begin{array}{l}\text { Serum iron } \\
\quad(\mathrm{mg} / \mathrm{dl})\end{array}$ & $100.68 \pm 24.33$ & $91.95 \pm 33.66$ & $83.78 \pm 19.74$ & 0.12 & & 2.23 & - & - & - & - \\
\hline $\begin{array}{l}\text { Glycemia } \\
(\mathrm{mg} / \mathrm{dl})\end{array}$ & $86.25 \pm 5.90$ & $85.82 \pm 0.69$ & $86.00 \pm 6.69$ & 0.82 & & 0.19 & - & - & - & - \\
\hline $\operatorname{ALT}^{\mathrm{a}}(\mathrm{U} / \mathrm{l})$ & $30.09 \pm 12.12$ & $35.22 \pm 9.52$ & $31.52 \pm 9.73$ & 0.03 & & 4.43 & 0.287 & 0.011 & 0.065 & 0.99 \\
\hline $\operatorname{AST}^{\mathrm{b}}(\mathrm{U} / \mathrm{l})$ & $29.48 \pm 7.08$ & $30.30 \pm 6.11$ & $29.74 \pm 5.55$ & 0.54 & 1.22 & & - & - & - & - \\
\hline $\mathrm{GGT}^{\mathrm{c}}(\mathrm{U} / \mathrm{l})$ & $38.04 \pm 8.77$ & $35.27 \pm 6.30$ & $36.26 \pm 6.54$ & 0.03 & 11.41 & & 0.284 & 0.001 & 0.31 & 0.16 \\
\hline $\begin{array}{l}\text { Total bilirubin } \\
\quad(\mathrm{mg} / \mathrm{dl})\end{array}$ & $0.83 \pm 0.28$ & $0.76 \pm 0.24$ & $0.88 \pm 0.30$ & 0.45 & 1.60 & & - & - & - & - \\
\hline $\mathrm{Hb}^{\mathrm{d}}(\mathrm{mg} / \mathrm{dl})$ & $14.54 \pm 1.29$ & $14.43 \pm 1.30$ & $14.46 \pm 1.34$ & 0.75 & & 0.29 & - & - & - & - \\
\hline $\mathrm{WBCs}^{\mathrm{e}}(\mu \mathrm{l})$ & $5894.26 \pm 1204.55$ & $5961.30 \pm 1660.25$ & $5862.60 \pm 1006.71$ & 0.96 & 0.09 & & - & - & - & - \\
\hline $\operatorname{RBCs}^{\mathrm{f}}(\mu \mathrm{l})$ & $4,786,698.70 \pm 456,834.83$ & $4,771,347.83 \pm 422,856.39$ & $4,749,173.91 \pm 463,205.50$ & 0.37 & & 0.83 & - & - & - & - \\
\hline $\operatorname{PLTs}^{\mathrm{g}}(\mu \mathrm{l})$ & $214,913.04 \pm 40,648.06$ & $221,121.74 \pm 47,352.44$ & $226,000 \pm 42,664.50$ & 0.24 & & 1.46 & - & - & - & - \\
\hline $\begin{array}{c}\text { Total plasma } \\
\text { protein }(\mathrm{mg} / \mathrm{dl})\end{array}$ & $6.99 \pm 0.30$ & $6.91 \pm 0.34$ & $6.99 \pm 0.37$ & 0.50 & & 0.70 & - & - & - & - \\
\hline
\end{tabular}

${ }^{*}$ Mean \pm standard deviation. ${ }^{* *}$ Overall P value of Repeated Measures ANOVA or Friedman test. ${ }^{* * *}$ Bonferroni or Wilcoxon test post hoc pairwise comparisons.

shows the comparison of the differences in biochemical blood parameters at $\mathrm{T} 0$, $\mathrm{T} 1$, and T2. Effect size estimates for the significant results are also reported.

Most of the biochemical parameters showed a distribution not significantly different from normality as tested by the Kolnmogorov-Smirnof test, except for creatininemia, AST, GGT, bilirubinemia and WBCs.

Regarding lipid metabolism, significant differences from baseline values were found in total cholesterol, LDL fraction and LDL/HDL ratio. More precisely, total cholesterol, LDL cholesterol, and LDL/HDL ratio were significantly lower in hazelnut-enriched diet period than during baseline period $(\mathrm{P}=0.01,0.03$ and 0.02 , respectively). In particular, 12 out of 24 voluntaries reached a relative re- 
duction of LDL above 10\%; 6 showed a reduction below $10 \%$, and only 6 presented an increment or no change from the initial value. However, all of these parameters significantly increased during the last 6 weeks-those without hazelnut consumption. No significant differences were observed in HDL nor in triacylglycerol contents among T0, T1, and T2. No significant changes were also observed in azotemia, serum iron, glycemia, AST, total bilirubin, Hb, WBCs, RBCs, platelet count, and total plasma proteins. Furthermore, hazelnut-enriched diet appeared to decrease uric acid concentration as the mean value decreased from $4.66 \mathrm{mg} / \mathrm{dl}$ (T0) to $4.31 \mathrm{mg} / \mathrm{dl}$ ( $\mathrm{T} 1)(\mathrm{P}=0.025)$, finally returning to the basal value at $\mathrm{T} 2$. A significant difference in this parameter was also found between $\mathrm{T} 1$ and $\mathrm{T} 2(\mathrm{P}=0.013)$, while there was no difference in uric acid values between T0 and T2. Significantly as well, creatinine decreased from $0.94 \mathrm{mg} / \mathrm{dl}$ (T0) to $0.93 \mathrm{mg} / \mathrm{dl}$ (T1), and finally dropped to $0.82 \mathrm{mg} / \mathrm{dl}$ (T2).

Within the normal ranges, a significant increment was observed for ALT during hazelnut-enriched diet (from $30.9 \mathrm{U} / \mathrm{L}$ to $35.22 \mathrm{U} / \mathrm{L}, \mathrm{P}=0.01$ ), while GGT significantly decreased from $38.04 \mathrm{mg} / \mathrm{dl}$ at $\mathrm{T} 0$ to $35.27 \mathrm{mg} / \mathrm{dl}$ at $\mathrm{T} 1(\mathrm{P}=0.001)$ and no significant differences were found comparing $\mathrm{T} 1$ and $\mathrm{T} 2$ or $\mathrm{T} 0$ and $\mathrm{T} 2$ for AST. Table 3 shows T0 - T1 $\Delta \%$ LDL between baseline LDL (lower or higher than $130 \mathrm{mg} / \mathrm{dl}$ ), BMI (higher or lower than $25 \mathrm{~kg} / \mathrm{m}^{2}$ ), age (older or younger than 55 years) and gender subgroups by Mann-Whitney $U$ test. A higher decrease was observed in females vs males $(-22.61$ vs -8.37$)$ and in the group with higher vs lower baseline LDL values ( -33.14 vs -20.02 ) but both differences were not statistically significant. In addition, no difference was observed between age and BMI subgroups. Furthermore no weight changes in voluntaries were observed as consequence of enriched-hazelnut diet.

\section{Discussion}

Considering the aforementioned potential, beneficial effects of dried fruit consumption, this trial aimed to assess the implications of daily hazelnut supplementation on lipid metabolism in healthy subjects. The data obtained showed

Table 3. T0 - T1 percentage LDL variation compared to initial LDL, BMI, gender and age.

\begin{tabular}{ccccc}
\hline \multirow{2}{*}{ Variable } & \multicolumn{3}{c}{ T0 vs. T1 } & $\mathbf{P}^{\mathrm{c}}$ \\
\cline { 2 - 5 } Sex & Males & 14 & Mean $\Delta \%$ LDL \pm SD $^{\mathrm{b}}$ & 0.68 \\
& Females & 10 & $-8.37 \pm 17.32$ & 0.34 \\
Age & $<55.5$ years old & 12 & $-20.61 \pm 18.91$ & 0.88 \\
Basal LDL (T0) & $\leq 130 \mathrm{mg} / \mathrm{dl}$ & 10 & $-17.36 \pm 22.51$ & $-16.23 \pm 23.64$ \\
& $>130 \mathrm{mg} / \mathrm{dl}$ & 14 & $-11.50 \pm 14.76$ & 0.82 \\
Basal BMI (T0) & $\leq 25 \mathrm{~kg} / \mathrm{m}^{2}$ & 11 & $-14.17 \pm 16.62$ & $-12.88 \pm 20.86$ \\
\hline
\end{tabular}

${ }^{\mathrm{a}}$ Number of subjects; ${ }^{\mathrm{b}}$ Standard deviation; ${ }^{\mathrm{c}}$ Mann-Whitney U test. 
that the use of hazelnuts in an amount of about $230 \mathrm{Kcal}$ of total daily energy intake might exhibit multiple complex effects on the general health status of these subjects. The results appear to support our primary outcome, being the confirmation of the beneficial effect of hazelnut assumption on cholesterol parameters and uric acid.

\subsection{Plasma Measurements}

Previous studies showed that hazelnut-enriched diets provide improvements on plasma lipid and lipoprotein levels in subjects affected by hypercholesterolemia [5] [21] [22]. Similar changes were also observed in clinical trials using other nuts [8] [22]. The mean estimated reduction of total and LDL cholesterol at the end of the enriched diet $(-16.61 \mathrm{mg} / \mathrm{dl}$ or $8.19 \%$ and $-13.91 \mathrm{mg} / \mathrm{dl}$ or $10.63 \%$, respectively) are of relevance. Indeed, it is noteworthy that these effects were observed despite the relatively low baseline cholesterol levels of the voluntaries. Although beneficial effects are generally attributed to nuts, each species has its own specific nutrition and nutraceutical profile that may provide different kinds and degrees of physiological effects on human metabolism. Hazelnuts (Corylus avellana L.) has a significant place among dried nuts in terms of nutrition and health, owing to the special composition of fat, protein, carbohydrate, vitamin, minerals, dietary fibers, and phenolic antioxidants [23] [24]. Although there are convincing evidences that fatty acids profile has favorable effect on blood lipid profile [25], a MUFA-enriched diet tends to raise blood HDL cholesterol and to lower triacylglycerol concentration [15]. The decrease in blood LDL oxidation level could also be related to vitamin E intake from hazelnut. Hazelnut-enriched diets increase vitamin $\mathrm{E}$ level and change the fatty acid profile of LDL particles, leading to a reduced concentration of plasma oxidized LDL. In our study we showed a lipid and lipoprotein lowering effects comparable to those achieved by Orem et al. [5] who used 49 - 86 gr/day natural raw hazelnuts. Alpha-tocopherol was the most dominant isomer in hazelnut, representing approximately $97.5 \%$ of the total tocopherols identified [26] [27] [28] [29] [30]. Its estimated mean value in cultivar Tonda Gentile Romana is about 240.00 ppm [11]. Among the three major tocopherols identified ( $\alpha$-, $\beta$-, $\gamma$-tocopherols), $\alpha$-tocopherol is the most active form in human and animal tissues [31] [32] due to the substitution pattern of the methyl groups on the chromanol ring making the hydrogen of the C- 6 hydroxyl group especially active, thereby facilitating the transfer of the hydrogen to a peroxyl radical [28] [29]. Furthermore, the possible mechanisms whereby hazelnut may improve lipid profile do not rely exclusively on the beneficial action of vitamin $\mathrm{E}$ in the kernel, but may include the effects of its concentration of PUFA, folic acid, copper, magnesium, protein (e.g., arginine), sterols, and phenolic components [9]. Hence, there may be multiple small effects contributing to the final result. No variations in triacylglycerol and glucose were observed because of hazelnut-enriched diet, as also reported in pistachio nut-based clinical trials [23] [33] [34]. In the present study, no variations in AST, serum iron, azotemia, total bilirubin, $\mathrm{Hb}$, WBCs, RBCs, platelet, total plasma protein content 
was found. Nevertheless, we observed that hazelnut intake can lower, serum urate level $(6.42 \pm 12.6 \Delta \%)$. After the hazelnut-enriched diet, uric acid and creatininemia mean values significantly decreased. The uric acid is a very strong antioxidant of our body, which becomes pro-oxidant at higher concentrations. The quantity and the quality of hazelnut pro-anthocyanidins (enriched in type A and type B), which represent the most abundantly found class of polyphenols in $\mathrm{Co}$ rylus [14] [35] [36], could be involved in this process. As reported by Sorlimar and Sarmalina, grape seeds intake in Gout-Animals Model were able to exert inhibitory effects on transcription factors like nuclear factor kappa b (NF-KB) or activator protein-1 (AP-1), with consequent beneficial effects in preventing high uric acid level and high blood pressure [37].

ALT and AST levels are two of the most important sensitive indicators of liver dysfunction in clinical diagnosis. A beneficial effect of vitamin E supplementation in optimizing aminotransferase levels was showed in patients with chronic liver diseases [38]. In this trial, we evidenced an unexpected significant increase of mean ALT levels, even though within the normal range, with a return to-initial values at T2 period. No patient reached values higher than $70 \mathrm{U} / \mathrm{L}$, which is the upper reference level of the laboratory where the analyses were performed. At the same time, no increase in ALT levels and a significant decrease in GGT levels (another important parameter of liver function) were observed. In an exploratory study like the present, it is difficult to postulate any physiological mechanism involved in the latter change that should be verified and deepened in a larger and more specific study. Based on the contemporary decrease in GGT, the stationary levels of AST and the increase of ALT within the normality levels, any liver damage should be excluded; nevertheless, these results encourage further studies on this topic opening new target in defying the role of hazelnut functional food. Our future perspectives will be to plan in vitro experimental trials in order to throw light on molecular mechanism involved in these results.

All plasma measurements evaluated at $\mathrm{T} 2$ significantly incremented towards the initial conditions (no significant differences were detected between T0 and T2). Therefore, most of the beneficial effects seem to be reversible after 6 weeks of a hazelnut-free diet as already demonstrated for the lipid profile [5]. None of the variables considered, including baseline LDL values, age, sex and BMI, seemed to influence significantly the change in LDL values observed between T0 and T1. Yet, considering also other possible confounding parameters, these outcomes should be analyzed on a larger scale study and with a higher statistical power.

\subsection{Strengths and Limitations}

The trial was structured on a crossover design, which is a suitable choice since the same experimental units (i.e., subjects) are given both treatments. This is able to reduce intra-subject variability and to provide information about residual effects after the conclusion of the hazelnut-enriched diet. So far, a very few number of studies have investigated the effects of a hazelnut-enriched diet on 
healthy subjects. Nevertheless, the characteristic of the present research is the multidisciplinary and exploratory approach that opens the way for a holistic interpretation of the individual's metabolic and health status as a prerequisite towards personalized nutrition.

A limitation of the current study may be represented by a limited sample size [39]. A randomized control study involving a larger group of participants could be suggested as it would be able to control for potentially confounding factor(s) that could interfere during the feeding periods.

\section{Conclusion}

Hazelnut intake improves blood lipid profile of healthy voluntaries. Although within the normal standard ranges, the changes observed in acid uric, serum creatinine, AST and GGT are useful to increase the knowledge on hazelnut functional food, possible unknown physiological mechanisms involved, as well as to select key specific target pathways to be evaluated by genomic and biochemical approaches. Our study confirmed also the reversibility of hazelnut-enriched diet benefits.

\section{Acknowledgements}

The authors thank the participants for their commitment and enthusiasm in participating to this study. We thank Dr. Fabio Vitali and Dr. Roberto Balducchi (laboratory coordinators) for assistance in planning the research experiments. We also wish to thank Dr. Antonio Di Mauro for his help in formatting and reviewing the manuscript. Our acknowledgements also to Dr. Alessandro Zini for suggestions in statistical elaboration. Finally, we express gratitude to Soc Coopernocciole for providing hazelnuts. As part of the "Research projects presented by Universities and Research Centers"-LR 13/2008, the work was founded by the Regional Education Directorate, Research and Innovation Research Area, Innovation and right to education of Regione Lazio Project BIOSERVICE Lr 13/2008 PROT. FILAS-RU-2014-1168 (October 2015-2017).

\section{References}

[1] Kushi, L.H., Folsom, A.R., Prineas, R.J., Mink, P.J., Wu, Y. and Bostick, R.M. (1996) Dietary Antioxidant Vitamins and Death from Coronary Heart Disease in Postmenopausal Women. The New England Journal of Medicine, 334, 1156-1162. https://doi.org/10.1056/NEJM199605023341803

[2] Fraser, G.E., Sabate, J., Beeson, W.L. and Strahan, T.M. (1992) A Possible Protective Effect of Nut Consumption on Risk of Coronary Heart Disease. Archives of Internal Medicine, 152, 1416-1424.

[3] Albert, C.M., Gaziano, J.M., Willett, W.C. and Manson, J.E. (2002) Nut Consumption and Decreased Risk of Sudden Cardiac Death in the Physicians' Health Study. Archives of Internal Medicine, 162, 1382-1387.

[4] Hu, F.B. and Willett, W.C. (2002) Optimal Diets for Prevention of Coronary Heart Disease. JAMA, 288, 2569-2578.

[5] Asım, O., Fulya Balaban, Y., Cihan, O., Buket, A., Birgeul Vanizor, K., Alasalvar, C., 
et al. (2013) Hazelnut-Enriched Diet Improves Cardiovascular Risk Biomarkers beyond a Lipid-Lowering Effect in Hypercholesterolemic Subjects. Journal of Clinical Lipidology, 7, 123-131. https://doi.org/10.1016/j.jacl.2012.10.005

[6] Kris-Etherton, P.M., Pearson, T.A., Wan, Y., Hargrove, R.L., Moriarty, K. and Fishell, V. (1999) High-Monounsaturated Fatty Acid Diets Lower Both Plasma Cholesterol and Triacylglycerol Concentrations. The American Journal of Clinical $\mathrm{Nu}$ trition, 70, 1009-1015.

[7] Rajaram, S., Burke, K., Connell, B., Myint, T. and Sabate, J. (2001) A Monounsaturated Fatty Acid-Rich Pecan-Enriched Diet Favorably Alters the Serum Lipid Profile of Healthy Men and Women. Journal of Nutrition, 131, 2275-2279.

[8] Kris-Etherton, P.M., Zhao, G., Binkoski, A.E., Coval, S.M. and Etherton, T.D. (2001) The Effects of Nuts on Coronary Heart Disease Risk. Nutrition Reviews, 59, 103-111. https://doi.org/10.1111/j.1753-4887.2001.tb06996.x

[9] Sabate, J., Haddad, E., Tanzman, J.S., Jambazian, P. and Rajaram, S. (2003) Serum Lipid Response to the Graduated Enrichment of a Step I Diet with Almonds: A Randomized Feeding Trial. The American Journal of Clinical Nutrition, 77, 13791384.

[10] Ros, E. (2009) Nuts and Novel Biomarkers of Cardiovascular Disease. The American Journal of Clinical Nutrition, 89, 1649S-1656S. https://doi.org/10.3945/ajen.2009.26736R

[11] Di Renzo, L., Carraro, A., Minella, D., Botta, R., Contessa, C., Sartor, C., Iacopino, A.M. and De Lorenzo, A. (2014) Nutrient Analysis Critical Control Point (NACCP): Hazelnut as a Prototype of Nutrigenomic Study. Food and Nutrition Sciences, 5, 79 88. https://doi.org/10.4236/fns.2014.51011

[12] Bacchetta, L. (2013) Hazelnuts and Almonds-Safeguard of Hazelnut and Almond Genetic Resources. Preserving Genetic Resources in Agriculture. European Commission, 114-119.

[13] Bacchetta, L., Rovira, M., Tronci, C., Aramini, M., Drogoudi, P., Silva, A.P., Solar, A., Avanzato, D., Botta, R., Valentini, N. and Boccacci, P. (2015) A Multidisciplinary Approach to Enhance the Conservation and Use of Hazelnut Genetic Resources. Genetic Resources and Crop Evolution, 62, 649-663.

https://doi.org/10.1007/s10722-014-0173-7

[14] Alasalvar, C. and Bolling, B.W. (2015) Review of Nut Phytochemicals, Fat-Soluble Bioactives, Antioxidant Components and Health Effects. British Journal of Nutrition, 113, S68-S78. https://doi.org/10.1017/s0007114514003729

[15] Parcerisa, J., Rafecas, M., Codony, R. and Boatella, J. (1999) Triacylglycerol and Phospholipid Composition of Hazelnut (Corylus avellana L.) Lipid Fraction during Development. Journal of Agricultural and Food Chemistry, 47, 1410-1415. https://doi.org/10.1021/jf980879q

[16] Friedewald, W.T., Levy, R.I. and Fredrickson, D.S. (1972) Estimation of the Concentration of Low-Density Lipoprotein Cholesterol in Plasma, without Use of the Preparative Ultra Centrifuge. Clinical Chemistry, 18, 499-502.

[17] Jacobs Jr., D.R. and Steffen, L.M. (2003) Nutrients, Foods, and Dietary Patterns as Exposures in Research: A Framework for Food Synergy. The American Journal of Clinical Nutrition, 78, 508-513.

[18] Faul, F., Erdfelder, E., Lang, A.-G. and Bunchner, A. (2007) GPower 3: A Flexible Statistical Power Analysis Program for the Social, Behavioral and Biomedical Sciences. Behavior Research Methods, 39, 175-191. https://doi.org/10.3758/BF03193146

[19] Leheman E.L. (2006) Nonparametrics: Statistical Methods Based on Ranks. Sprin- 
ger, New York.

[20] Tomczak M. and Tomczak E. (2014) The Need to Report Effect Size Estimates Revisited. Trends in Sport Sciences, 1, 19-25.

[21] Mercanligil, S.M., Arslan, P., Alasalvar, C., Okut, E., Akgül, E., Pinar, A., Geyik, P.Ö., et al. (2007) Effects of Hazelnut-Enriched Diet on Plasma Cholesterol and Lipoprotein Profiles in Hypercholesterolemic Adult Men. European Journal of Clinical Nutrition, 61, 212-220. https://doi.org/10.1038/sj.ejcn.1602518

[22] Tey, S.L., Brown, R.C., Chisholm, A.W., Delahunty, C.M., Gray, A.R., and Williams, S.M. (2011) Effects of Different Forms of Hazelnuts on Blood Lipids and $\alpha$-Tocopherol Concentrations in Mildly Hypercholesterolemic Individuals. European Journal of Clinical Nutrition, 65, 117-124. https://doi.org/10.1038/ejcn.2010.200

[23] Edwards, K., Kwaw, I., Matud, J. and Kurtz, I. (1999) Effect of Pistachio Nuts on Serum Lipid Levels in Patients with Moderate Hypercholesterolemia. Journal of the American College of Nutrition, 18, 229-232.

[24] Demirbas, A. (2007) Phenolics from Hazelnut Kernels by Supercritical Methanol Extraction. Energy Sources Part A, 29, 791-797.

[25] Simsek, A. and Aykut, O. (2007) Evaluation of the Microelement Profile of Turkish Hazelnut (Corylus avellana L.) Varieties for Human Nutrition and Health. International Journal of Food Sciences and Nutrition, 58, 677-688.

[26] Cosmulescu, S., Botu, M. and Trandafir, I. (2013) The Mineral Source for Human Nutrition of Nuts in Different Hazelnut (Corylus avellana L.) Cultivars. Notulae Botanicae Horti Agrobotanici Cluj-Napoca, 41, 250-254.

[27] Santi, C., Toriani Terenzi, C., Minocchi, R., Giorni, A., Di Renzo, L., Valente, R., De Lorenzo, A. and Bacchetta, L. (2014) Cibi funzionali: La nocciola come modello di studio. Giornata Divulgativa Università Tor Vergata 4 Dicembre 2014.24.

[28] Sivakumar, G., Bacchetta, L., Gatti, R. and Zappa, G. (2005) HPLC Screening of Natural Vitamin E from Mediterranean Plant Biofactories-A Basic Tool for Pilot-Scale Bioreactors Production of $\alpha$-Tocopherol. Journal of Plant Physiology, 162, 1280-1283. https://doi.org/10.1016/j.jplph.2005.04.018

[29] Sivakumar, G. and Bacchetta, L. (2005) Determination of Natural Vitamin E from Italian Hazelnut Leaves. Chemistry of Natural Product, 41, 654-656. https://doi.org/10.1007/s10600-006-0005-x

[30] Solar, A. and Stampar, F. (2011) Characterization of Selected Hazelnut Cultivars: Phenology, Growing and Yielding Capacity, Market Quality and Nutraceutical Value. Journal of the Science of Food and Agriculture, 91, 1205-1212. https://doi.org/10.1002/jsfa.4300

[31] Alasalvar, C., Amaral, J.S., Satirm G., and Shahidi, F. (2009) Lipid Characteristics and Minerals of Native Turkish Hazelnut Essential Varieties (Corylus avellana L.). Food Chemistry, 113, 919-925. https://doi.org/10.1016/j.foodchem.2008.08.019

[32] Kornsteiner, M., Wagner, K.H. and Elmadfa, I. (2006) Tocopherols and Total Phenolics in 10 Different Nut Types. Food Chemistry, 98, 381-387. https://doi.org/10.1016/j.foodchem.2005.07.033

[33] Li, Z., Song, R. and Nguyen, C. (2010) Pistachio Nuts Reduce Triglycerides and Body Weight by Comparison to Refined Carbohydrate Snack in Obese Subjects on a 12-Week Weight Loss Program. The Journal of the American College of Nutrition, 29, 198-203.

[34] Sari, I., Baltaci, Y. and Bagci, C. (2010) Effect of Pistachio Diet on Lipid Parameters, Endothelial Function, Inflammation, and Oxidative Status: A Prospective Study. Nutrition, 26, 399-404. https://doi.org/10.1016/j.nut.2009.05.023 
[35] Chen, C.Y., Milbury, P.E., Lapsley, K. and Blumberg, J.B. (2005) Flavonoids from Almond Skins Are Bioavailable and Act Synergistically with Vitamins C and E to Enhance Hamster and Human LDL Resistance to Oxidation. Journal of Nutrition, 135, 1366-1373.

[36] Chen, C.Y. and Blumberg, J.B. (2008) Phytochemical Composition of Nuts. Asia Pacific Journal of Clinical Nutrition, 17, 329-332.

[37] Sonlimar, M. and Sarmalina, S. (2010) Effect of Grape (Vitis vinifera L.) Seed on Reducing Serum Uric Acid Level in Gout-Animals Model. Majalah Kesehatan Pharmamedika, 2, 106-109.

[38] Ji, H.-F., Sun, Y. and Shen, L. (2014) Effect of Vitamin E Supplementation on Aminotransferase Levels in Patients with NAFLD, NASH, and CHC: Results from a Meta-Analysis. Nutrition, 30, 986-991. https://doi.org/10.1016/j.nut.2014.01.016

[39] García-Segura, L., Pérez-Andrade, M. and Miranda-Ríos, J. (2013) The Emerging Role of MicroRNAs in the Regulation of Gene Expression by Nutrients. Journal of Nutrigenetics and Nutrigenomics, 6, 16-31. https://doi.org/10.1159/000345826

\section{Scientific Research Publishing}

Submit or recommend next manuscript to SCIRP and we will provide best service for you:

Accepting pre-submission inquiries through Email, Facebook, LinkedIn, Twitter, etc. A wide selection of journals (inclusive of 9 subjects, more than 200 journals)

Providing 24-hour high-quality service

User-friendly online submission system

Fair and swift peer-review system

Efficient typesetting and proofreading procedure

Display of the result of downloads and visits, as well as the number of cited articles

Maximum dissemination of your research work

Submit your manuscript at: http://papersubmission.scirp.org/

Or contact fns@scirp.org 